\title{
Increased Need for Gastrointestinal Surgery and Increased Risk of Surgery-Related Complications in Patients with Ehlers-Danlos Syndrome: A Systematic Review
}

\author{
Marie-Louise Kulas Søborg Julie Leganger Jacob Rosenberg Jakob Burcharth \\ Department of Surgery, Center for Perioperative Optimization (CPO), Gastro Unit, Herlev Hospital, Herlev, Denmark
}

\section{Key Words}

Colorectal surgery · Complications · Lower gastrointestinal bleeding

\begin{abstract}
Background/Aims: Ehlers-Danlos syndromes (EDSs) constitute a rare group of inherited connective tissue diseases, characterized by multisystemic manifestations and general tissue fragility. Most severe complications include vascular and gastrointestinal (Gl) emergencies requiring acute surgery. The purpose of this systematic review was to assess the causes of Gl-related surgery and related mortality and morbidity in patients with EDSs. Methods: A systematic search was conducted in PubMed, Embase, and Scopus to identify relevant studies. Preferred Reporting Items for Systematic Reviews and Meta-Analysis guidelines for systematic reviews were followed. According to eligibility criteria, data were extracted and systematically screened by 2 authors. Results: Screening process identified 11 studies with a total of 1,567 patients. Findings indicated that patients with EDSs had a higher occurrence of surgery demanding GI manifestations, including perforation, hemorrhage, rupture of intraabdominal organs, and rectal prolapse. Most affected was the vascular subtype, of which up to $33 \%$ underwent GI surgery and suffered from a lowered average life expectancy of
\end{abstract}

48 years (range 6-78). Secondary complications of surgery were common in all patients with EDSs. Conclusion: Studies suggested that patients with EDSs present an increased need for GI surgery, but also an increased risk of surgery-related complications, most predominantly seen in the vascular subtype.

(c) 2016 S. Karger AG, Basel

\section{Introduction}

The Ehlers-Danlos syndromes (EDSs) comprise a clinically and genetically highly heterogeneous group of connective tissue disorders caused by alterations in collagen synthesis. The pathogenesis behind EDSs is mutations in the collagen coding genes, resulting in quantitative and qualitative abnormalities in collagen I, III, and V $[1,2]$. EDSs are characterized by a multisystemic nature with cardinal features being skin hyperextensibility and fragility, easy bruising, widened atrophic scarring, joint hypermobility, and general fragility of the connective tissues with rupture of vascular and internal organs [3]. Furthermore, a large proportion of patients with EDSs report symptoms from the gastrointestinal (GI) system [4], from cavum oris to the rectum, including the abdominal vasculature [5] (table 1). The current Villefranche classifica-

\section{KARGER}

E-Mail karger@karger.com

www.karger.com/dsu
(C) 2016 S. Karger AG, Basel

0253-4886/16/0342-0161\$39.50/0 
Table 1. GI manifestations in subtypes of EDSs

\begin{tabular}{|c|c|}
\hline EDSs subtype & GI manifestations \\
\hline Classic (I + II) & $\begin{array}{l}\text { Rectal prolapse } \\
\text { Megacolon } \\
\text { Recurrent hernias (inguinal, umbilical, incisional, hiatal) } \\
\text { Spontaneous rupture of large vessels and bowel }\end{array}$ \\
\hline Hypermobility (III) & $\begin{array}{l}\text { Functional GI disorders: } \\
\text { Chronic abdominal pain } \\
\text { Nausea } \\
\text { Vomiting } \\
\text { IBS symptoms } \\
\text { Constipation } \\
\text { GERD } \\
\text { Postprandial fullness } \\
\text { Dyspepsia } \\
\text { Dysmotility } \\
\text { Abnormal/delayed/accelerated gastric emptying } \\
\text { GI bleeding } \\
\text { Rectal prolapse } \\
\text { Recurrent hernias (inguinal, umbilical, incisional, hiatal) } \\
\text { Diverticulosis }\end{array}$ \\
\hline Vascular (IV) & $\begin{array}{l}\text { Spontaneous abdominal hemorrhage } \\
\text { Spontaneous bowel, spleen, and liver rupture } \\
\text { High frequency of surgical complications } \\
\text { Venous varices } \\
\text { Recurrent hernias (inguinal, umbilical, incisional, hiatal) } \\
\text { Colonic diverticulosis }\end{array}$ \\
\hline Kyphoscoliotic (VI) & $\begin{array}{l}\text { GERD } \\
\text { Spontaneous rupture of large vessels }\end{array}$ \\
\hline \multicolumn{2}{|l|}{ Arthrochalasia (VIIa + b) } \\
\hline Dermatosparaxis (VIIc) & $\begin{array}{l}\text { Bladder rupture } \\
\text { Diaphragm rupture } \\
\text { Recurrent hernias (inguinal, umbilical, incisional) }\end{array}$ \\
\hline
\end{tabular}

Adapted from $[2,4,6]$. IBS = Irritable bowel syndrome; GERD = gastroesophageal reflux disease.

tion recognizes 6 clinical subtypes of EDSs [7] (table 2), each clinically diagnosed according to defined minor and major criteria, and each presenting with a broad variety in penetrance and severity of clinical symptoms and outcomes after surgical procedures [8]. The prevalence of EDSs is estimated between 1:1,000 and 1:25,000 [8], of which the classic, hypermobility, and vascular types are most common $[1,8]$.

Patients with EDSs have been reported to be suffering from increased morbidity and mortality in relation to surgical procedures due to primary manifestations and secondary complications, both pre- and post-operatively [5, 11-13]. Again, surgical need and associated complications present with great heterogeneity within the different subtypes. The most severe presentations are seen among the vascular subtype and include acute vascular and GI emergencies [7]. Hence, patients with EDSs are fragile to surgery as a logical consequence of their altered collagen structure, but still present a frequent need for surgical intervention [14]. In spite of this, limited awareness and knowledge among surgeons exists on this vulnerable patient group along with when to and how to operate. This applies specifically to GI surgery as very few original studies exist and no official surgical guidelines currently are at hand.

The aim of this systematic review was to delineate the causes of GI-related surgery with variation within the different subtypes and to estimate the reported mortality 
Table 2. Classification and clinical presentation of EDSs subtypes according to Villefranche nosology 1997 [7]

\begin{tabular}{|c|c|c|c|c|}
\hline EDSs subtype & Cardinal symptoms & $\begin{array}{l}\text { Inheritance } \\
\text { pattern }\end{array}$ & Affected protein & $\begin{array}{l}\text { Genetic } \\
\text { mutation }\end{array}$ \\
\hline Classic (I + II) & $\begin{array}{l}\text { Skin hyperextensibility } \\
\text { Widened atrophic scarring } \\
\text { Joint hypermobility and dislocations } \\
\text { Easy bruising }\end{array}$ & $\mathrm{AD}$ & $\begin{array}{l}\text { Procollagen type V } \\
\text { Procollagen type I }\end{array}$ & $\begin{array}{l}\text { COL5A1 } \\
\text { COL5A2 } \\
(\text { COL1A1) }\end{array}$ \\
\hline Vascular (IV) & $\begin{array}{l}\text { Severe bleeding tendency, excessive bruising } \\
\text { Thin, translucent skin } \\
\text { Spontaneous arterial, intestinal, splenic, and uterine } \\
\text { rupture } \\
\text { Characteristic facial features } \\
\text { (spontaneous pneumothorax, recurrent joint } \\
\text { dislocations, high frequency of surgical complications) }\end{array}$ & $\mathrm{AD}$ & Procollagen type III & $\begin{array}{l}\text { COL3A1 } \\
\text { Many sporadic } \\
\text { cases without } \\
\text { familial relation }\end{array}$ \\
\hline Kyphoscoliosis (VI) & $\begin{array}{l}\text { Kyphoscoliosis at birth } \\
\text { Severe muscular hypotonia at birth } \\
\text { Generalized joint laxity } \\
\text { Scleral fragility and spontaneous rupture of bulbus oculi } \\
\text { Easy bruising }\end{array}$ & AR & Lysyl hydroxylase-1 & PLOD1 \\
\hline $\begin{array}{l}\text { Arthrochalasia } \\
(\text { VII }+b)\end{array}$ & $\begin{array}{l}\text { Severe generalized joint hypermobility and subluxations } \\
\text { Congenital bilateral hip dislocation } \\
\text { Skin hyper extensibility } \\
\text { Widened atrophic scarring }\end{array}$ & $\mathrm{AD}$ & $\begin{array}{l}\text { Procollagen type I } \\
\text { loss of N-propeptide } \\
\text { cleavage site }\end{array}$ & $\begin{array}{l}\text { COL1A1 } \\
\text { COL1A2 }\end{array}$ \\
\hline $\begin{array}{l}\text { Dermatosparaxis } \\
\text { (VIIc) }\end{array}$ & $\begin{array}{l}\text { Severe skin fragility } \\
\text { Sagging, redundant skin } \\
\text { Excessive bruising } \\
\text { Characteristic facies }\end{array}$ & $\mathrm{AR}$ & $\begin{array}{l}\text { Procollagen-I-N- } \\
\text { proteinase }\end{array}$ & ADAMTS-2 \\
\hline
\end{tabular}

Others

Cardiac-valvular, vascular-like, tenascin-X deficient, progeroid, B3GALT6 deficient, musculocontractural, FKBP14-related, spondylocheirodysplastic, EDSs with periventricular heterotopia, EDSs with periodontitis

Adapted from $[1-3,8-10] . \mathrm{AD}=$ Autosomal dominant; $\mathrm{AR}=$ autosomal recessive.

and morbidity to both GI surgery and general surgical complications in patients with EDSs. The review also seeks to raise awareness among GI surgeons on the EDSs patient group and furthermore provide current recommendations on GI-related surgical procedures to lower the mortality and increase the quality of life of patients with EDSs [11].

\section{Material and Methods}

A systematic review was conducted using the Preferred Reporting Items for Systematic reviews and Meta-Analysis (PRISMA) guidelines [15]. The review protocol was per- formed according to the PRISMA-P guideline [16] and registered at the PROSPERO database [17] with registration number CRD42015027619.

All original studies concerning patients with EDSs, with diagnosis confirmed according to Villefranche criteria or diagnosed members of national EDSs foundations, were considered for full-text-screening, describing primary GI manifestations requiring surgery and associated mortality and morbidity to GI surgery, both acute and elective. Eligibility criteria were: all observational studies, randomized clinical trials, and case series including more than 10 patients. We considered both retrospective and prospective studies. No limitations of publication date were applied due to the pre-expectation of a limited number of studies published. Only published literature in English, Danish, Swedish, and Norwegian were eligible for inclusion, and meeting 


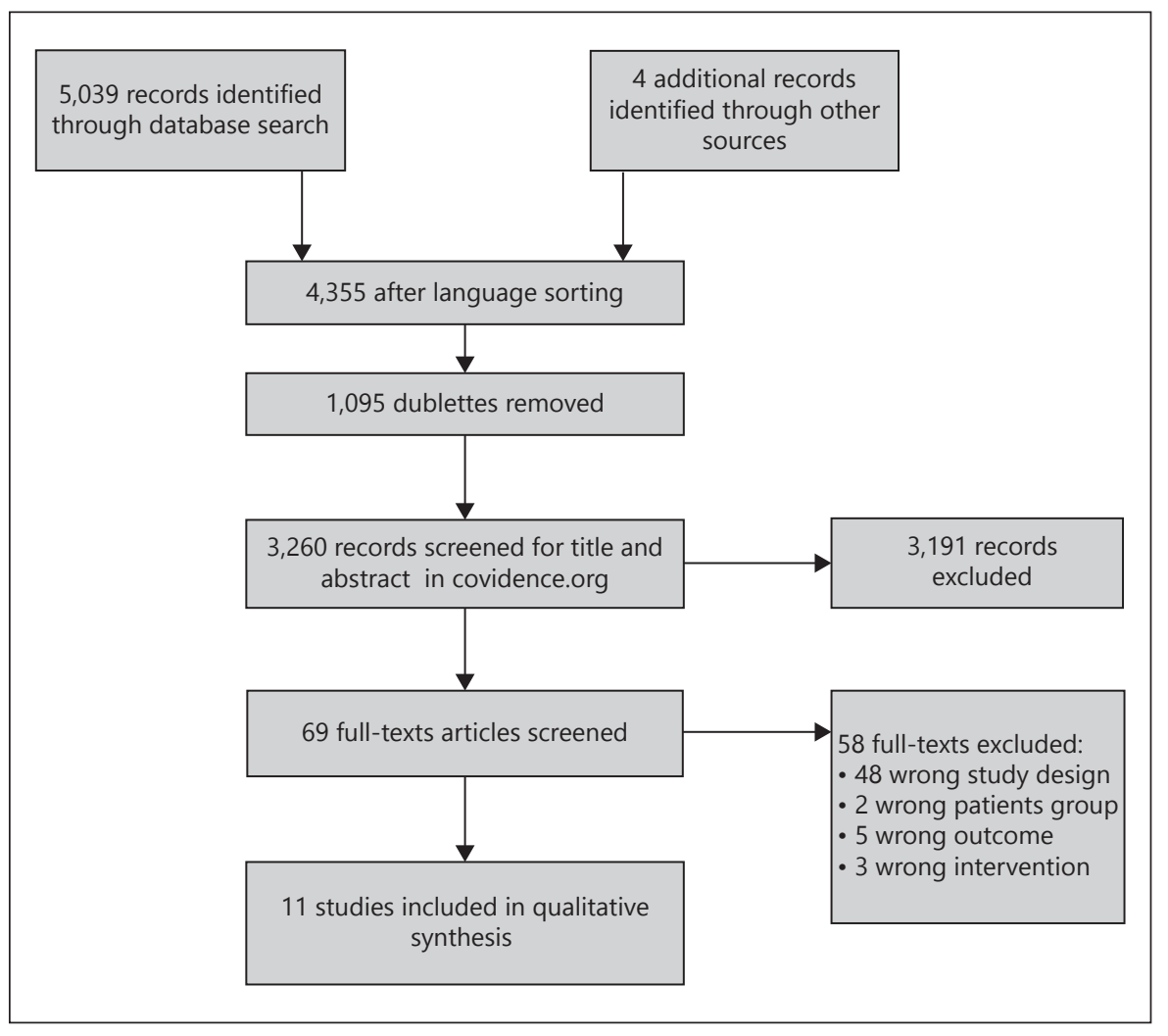

Fig. 1. PRISMA flow-chart [15].

abstracts, correspondence letters, editorials, abstracts, reviews, and case reports or case series with less than 10 patients were excluded.

\section{Information Sources}

A literature search was conducted on September 23, 2015 by applying the developed search strategy to PubMed, Embase, and Scopus. For PubMed and Embase the following search was applied: (Ehlers Danlos syndrome OR Ehlers Danlos disease OR Ehlers Danlos) AND (general surgery OR surgery OR surgical OR procedures OR traumatology OR trauma OR injury OR operative OR operation OR operative procedures OR surgical procedures, operative OR operative surgical procedures OR operative management OR perioperative management OR treatment OR treatment methods OR treatment procedures OR colposcopy OR sigmoidoscopy OR endoscopic OR colorectal surgery OR colostomy OR ileostomy OR resection OR management OR operation OR sigmoidoscopy OR colonoscopy OR invasive). The search was subsequently modified to fit Scopus's terminology.

The search strategy was deliberately made wide, and an additional search for unpublished clinical trials using the WHO trial search function [18] did not locate any relevant unpublished studies for this review.

\section{Study Selection}

References from all sources were gathered in Endnote X7.3 (Thomson Reuters, US), where exclusion based on language and duplication was executed. Title and abstract screening was conducted by 2 independent authors (M.-L.K.S. and J.L.) via the online tool at covidence.org [19]. All but 10 records were retrieved in fulltext (fig. 1) and assessed by the same 2 authors (M.-L.K.S. and J.L.), and additionally a snowball search was performed, examining articles cited by the relevant articles. Discrepancies in any part of the screening process were solved by discussion or if necessary with a third author (J.B.).

\section{Data Collection and Data Items}

Data from included studies were extracted into a predefined Microsoft Excel sheet (2010 Microsoft Corporation; Redmond, Wash., USA) containing article information (author, year, study design), patient demographics (EDSs type), and outcomes (mortality rate, GI-specific complications, general surgical complications, debut age of first severe complication).

\section{Data Synthesis and Bias Assessment}

All outcomes were reported. According to the protocol, metaanalysis would be performed on any outcomes where possible; however this was not possible due to incomparability of study designs and outcomes.

All studies were individually assessed for risk of bias by the Newcastle Ottawa Scale (NOS) for observational studies [20], using the cohort studies model and reported as a median value with range as recommended by the Cochrane collaboration for detecting bias in non-randomized studies [20]. The NOS is a scale-based system (range 0-9), where high scores indicate low risk of bias and low scores indicate high risk of bias. To simplify the interpretation of the NOS scores, we grouped scores 1-3 as high risk of bias, 4-6 as moderate risk of bias, and 7-9 as low risk of bias. 


\section{Results}

The literature search identified an initial 5,039 records, of which 76 potential articles were identified and read in full text. Of these, 48 studies were excluded, being case studies and literature reviews (fig. 1). Two studies presented a wrong patient group, 5 reported outcomes related to vascular surgery, and 3 held vascular interventions, and were excluded. The remaining 11 studies met the study eligibility criteria, of which 2 studies held the same 100 patients as a continuum [21, 22], and altogether summed 1,567 patients $[4,13,21,29]$. In total, 1,312 patients had the diagnosis confirmed by Villefranche criteria, while the remaining patients were retrieved from national EDSs foundations and health clinics with no reported method of diagnosis. The included studies provided data on GI surgery in general, colostomies, hernia repair, surgery of organ rupture, and GI hemorrhage (table 3).

Risk of bias within studies, assessed by NOS, presented a median value of 3 (range 1-6). The general low scores reflected study designs inadequate in consistency and evidence, caused by self-report bias in questionnaires and personal observations/case series and selection bias on patients selected from the national foundations and various medical and genetic centers. In addition, studies held detection bias towards the vascular subtype, as the only included large-scale original study [13], reporting the bulk of predefined outcomes in this review, was conducted in patients with the vascular subtype.

\section{Mortality and GI Manifestations}

In general, a high occurrence of GI-related symptoms were seen in all subtypes of EDSs, affecting over $50 \%$ of patients with EDSs altogether, varying from mild functional to severe manifestations (table 4). Acute complications were most prevalent in the vascular subtype, both primary manifestations that needed surgical intervention and secondary post-surgical complications. Functional GI symptoms were more prevalent in the hypermobility type and to a lesser extent in the classic type [4]. Reduced life expectancy could not be proven as a general feature of EDSs. Only the vascular subtype showed a lowered average life expectancy of 48 years (range 6-73 years) due to a reported 22 -year mortality of $31 \%$. The increased mortality was associated with vascular rupture with $38 \%$ mortality and spontaneous GI rupture with $10 \%$ mortality [13, 30].

GI Surgery in Patients with EDSs
Rupture of Hollow or Solid Organ Viscus

Spontaneous rupture of a hollow viscus or solid organ in the abdominal cavity (e.g. intestines, liver, spleen, uterus, and bladder) presents clinically as acute abdominal pain. The occurrence of organ rupture was primarily seen in patients with vascular EDSs, of whom up to 25\% [29] had experienced a rupture of one of the mentioned structures. This was associated with a total mortality of $16 \%$ [13]. Occurrence in other subtypes of EDSs was reported as low as $11 \%$ in a cohort of all EDSs subtypes [21], while a single study showed a lifetime incidence of $19 \%$ in the hypermobility type [24].

The most frequent type of rupture was spontaneous perforation of the GI tract, with a clear predilection for the sigmoid colon followed by small intestine and stomach [13]. Spontaneous GI perforation was reported most frequently in the vascular subtype, where it constituted $82 \%$ of all GI complications. In this group, the mean age at first occurrence was 24 (SD 11) years, and therefore averagely constituted the earliest complication type in patients with vascular subtype, compared with arterial or solid organ rupture [13]. The mortality from isolated intestinal perforation was reported to be $12 \%$ in the vascular subtype, and consistently gave rise to acute surgical intervention [13]. The intestinal perforations were predominantly closed by resection, followed by a colostomy or less frequently a primary end-to-end anastomosis. The reperforation rate of the intestine after end-to-end ileorectal anastomosis was considerably higher than after colostomy, 67 vs. $27 \%$, and had a mortality of $12 \%$ [13]. No data on mortality or reperforation rate after surgery was found for other EDSs subtypes than the vascular subtype.

\section{Hernia}

Herniation (inguinal, femoral, umbilical, and incisional hernia) had an overall incidence as a primary manifestation of up to 19\% [21] in patients with EDSs as an overall group, of which the vascular subtype had as high a prevalence as $23 \%$ [27]. One included study compared the risk of inguinal hernia in patients with EDSs with the background population and found a crude rate ratio of 2.5 (95\% CI 1.6-3.8) [24], indicating a significantly higher risk of inguinal herniation in all types of EDSs. No records were found on hernia-associated mortality, and the presence of a hernia therefore tends to be considered as a very rare risk factor for mortality in patients with EDS. 
Table 3. Overview of included studies

\begin{tabular}{|c|c|c|c|c|c|c|c|c|c|}
\hline Study & Year & Study-type & $\begin{array}{l}\text { Subjects, } \\
\mathrm{n}\end{array}$ & EDSs-type & $\begin{array}{l}\text { Villefranche } \\
\text { criterias }\end{array}$ & $\begin{array}{l}\text { Time- } \\
\text { period }\end{array}$ & $\begin{array}{l}\text { Control- } \\
\text { group }\end{array}$ & Outcomes subjects & $\begin{array}{l}\text { NOS- } \\
\text { score }\end{array}$ \\
\hline Nelson et al. [4] & 2015 & $\begin{array}{l}\text { Retrospective } \\
\text { database study }\end{array}$ & 687 & $\begin{array}{l}\text { Classic }(\mathrm{I}+\mathrm{II})(\mathrm{n}=73) \\
\text { Hypermobility }(\mathrm{III})(\mathrm{n}=471) \\
\text { Vascular }(\mathrm{IV})(\mathrm{n}=57) \\
\text { EDS other }(\mathrm{n}=86)\end{array}$ & + & 1994-2013 & - & $\begin{array}{l}\text { Rectal prolapse } \\
\text { GI surgery } \\
\text { Endoscopy }\end{array}$ & 6 \\
\hline Pepin et al. [13] & 2000 & $\begin{array}{l}\text { Retrospective } \\
\text { database study }\end{array}$ & 419 & Vascular (IV) $(\mathrm{n}=419)$ & + & 1974-1998 & - & $\begin{array}{l}\text { Spontaneous bowel } \\
\text { rupture } \\
\text { Viscus organ rupture } \\
\text { GI surgery } \\
\text { Reperforation } \\
\text { Surgery mortality }\end{array}$ & $\begin{array}{l}2 \\
e\end{array}$ \\
\hline $\begin{array}{l}\text { Beighton et al. } \\
{[21]}\end{array}$ & 1969 & $\begin{array}{l}\text { Personal } \\
\text { observation/ } \\
\text { case series }\end{array}$ & 125 & $\begin{array}{l}\text { Classic }(\mathrm{I}+\mathrm{II}) \\
\text { Hypermobility (III), } \\
\text { Vascular (IV) } \\
(\mathrm{n}=125)\end{array}$ & - & - & - & $\begin{array}{l}\text { GI hemorrhage } \\
\text { Spontaneous bowel } \\
\text { rupture } \\
\text { Rectal prolapse } \\
\text { Hernia }\end{array}$ & 4 \\
\hline Beighton [22] & 1970 & $\begin{array}{l}\text { Personal } \\
\text { observations/ } \\
\text { case series }\end{array}$ & 100 & $\begin{array}{l}\text { Classic }(\mathrm{I}+\mathrm{II})(\mathrm{n}=77) \\
\text { Hypermobility }(\mathrm{III})(\mathrm{n}=11) \\
\text { Vascular }(\mathrm{IV})(\mathrm{n}=4) \\
\text { EDS other }(\mathrm{n}=8)\end{array}$ & - & - & - & $\begin{array}{l}\text { GI hemorrhage } \\
\text { Spontaneous bowel } \\
\text { rupture } \\
\text { Rectal prolapse } \\
\text { Hernia }\end{array}$ & 4 \\
\hline Fogel [23] & 2013 & $\begin{array}{l}\text { Personal } \\
\text { observations/ } \\
\text { case series }\end{array}$ & 15 & $\begin{array}{l}\text { Classic (I + II), } \\
\text { Hypermobility (III), } \\
\text { Vascular (IV) } \\
(\mathrm{n}=15)\end{array}$ & + & - & - & $\begin{array}{l}\text { Spontaneous bowel } \\
\text { rupture } \\
\text { Hernia } \\
\text { Surgery mortality }\end{array}$ & 5 \\
\hline $\begin{array}{l}\text { Castori et al. } \\
{[24]}\end{array}$ & 2010 & $\begin{array}{l}\text { Retrospective } \\
\text { questionnaire }\end{array}$ & 21 & Hypermobility (III) $(\mathrm{n}=21)$ & + & 2007-2009 & - & $\begin{array}{l}\text { Rectal prolapse } \\
\text { Hernia }\end{array}$ & 1 \\
\hline Liem et al. [25] & 1997 & $\begin{array}{l}\text { Retrospective } \\
\text { questionnaire }\end{array}$ & 130 & $\begin{array}{l}\text { Classic }(I+I I)(n=53) \\
\text { Hypermobility }(I I I)(n=55) \\
\text { Vascular }(I V)(n=7) \\
\text { EDS other }(n=15)\end{array}$ & - & - & + & Hernia & 5 \\
\hline $\begin{array}{l}\text { Rombaut et al. } \\
{[26]}\end{array}$ & 2011 & $\begin{array}{l}\text { Retrospective } \\
\text { questionnaire }\end{array}$ & 79 & Hypermobility (III) $(\mathrm{n}=79)$ & + & - & - & $\begin{array}{l}\text { General surgery } \\
\text { GI surgery }\end{array}$ & 1 \\
\hline $\begin{array}{l}\text { Oderich et al. } \\
{[27]}\end{array}$ & 2005 & $\begin{array}{l}\text { Retrospective } \\
\text { database study }\end{array}$ & 31 & Vascular (IV) $(\mathrm{n}=31)$ & + & - & - & $\begin{array}{l}\text { Hernia } \\
\text { GI surgery } \\
\text { Mortality }\end{array}$ & 5 \\
\hline Ritelli et al. [28] & 2013 & Case series & 40 & Classic $(I+I I)(n=40)$ & + & - & - & Hernia & 1 \\
\hline $\begin{array}{l}\text { Shimaoka et al. } \\
\text { [29] }\end{array}$ & 2010 & Case series & 20 & $\operatorname{Vascular}(I V)(\mathrm{n}=20)$ & + & - & - & $\begin{array}{l}\text { Spontaneous bowel } \\
\text { rupture }\end{array}$ & 1 \\
\hline
\end{tabular}

\section{Rectal Prolapse}

Prolapse of the rectum was shown to be most prevalent in children or infants [18], with an overall incidence of up to $4 \%$ [22] in patients with EDSs. Within the different subtypes, the included studies reported the highest incidence in the hypermobility type. Notably, rectal prolapse was not shown to be specifically associated with vascular EDS, which holds the highest rate for ruptured GI structures [4]. No data was reported on mortality, preferred surgical technique for managing rectal prolapse, or complications secondary to surgical intervention. 
Table 4. GI outcomes for included studies

\begin{tabular}{|c|c|c|c|c|c|c|}
\hline Subjects, $\mathrm{n}$ & 243 & 626 & 538 & 109 & 1,467 & \\
\hline Villefranche verified diagnosis & 190 & 571 & 531 & 94 & 1,377 & \\
\hline GI symptoms, \% & 58.9 & 57.5 & 47.4 & 43.0 & 56.0 & {$[4]$} \\
\hline GI surgery, \% & 11.6 & $8.1-35.7$ & $20.7-33.3$ & 8.1 & 10.1 & {$[4,13]$} \\
\hline GI perforation ${ }^{1}, \%$ & & 19.0 & $13.4-25.0$ & & 0.8 & {$[4,21,24,26,27]$} \\
\hline Rectal prolapse, $\%$ & 2.3 & 3.7 & 0 & 0 & $2.9-4.0$ & {$[4,22]$} \\
\hline GI-associated mortality, \% & & & $0-16.3$ & & 6.67 & {$[13,23,27]$} \\
\hline
\end{tabular}

GI Hemorrhage

Rupture and lesions of the general vasculature in patients with EDSs is predominantly a characteristic feature of the vascular subtype, in which $50 \%$ of the vascular complications are located in the thoracic or abdominal cavity $[1,13,31]$. The affected GI vessels are most commonly medium-sized arteries, for example, mesenteric, renal, or splenic arteries $[1,31]$, and the pathologic mechanism behind is the formation of aneurysms, spontaneous vascular dissection, spontaneous rupture, or fistulae formation. Data showed that $7 \%$ of all patients with EDSs experienced GI hemorrhage with clinical manifestation as hematemesis, melaena, or intramural hemorrhage [21, 22 ], but no data was available on the variation within the different subtypes. Neither was any report found on the mortality associated with GI hemorrhage.

\section{GI Diverticulosis}

A total of $4 \%$ of patients with EDSs were diagnosed with diverticulosis [22]. Interestingly, when undergoing colonoscopy, a higher number of up to $10 \%$ were found with GI diverticulosis, indicating that the prevalence might be significantly higher if all patients with EDSs were examined radiologically or endoscopically [4].

\section{Surgical Intervention}

Data showed that GI surgery had been performed in $10 \%$ of all patients with EDSs, but with a higher incidence of up to $33 \%$ of the vascular subtype [4]. For this group, the need for surgery other than GI surgery, both surgery for arterial dissection or rupture, spontaneous bowel perforation or organ rupture, altogether constituted as high a figure as $68 \%$ [13]. The included studies did not report precise data on the associated mortality when operated. However, a single study indicated a low mortality at $2 \%$ after GI surgery, compared with the highest surgery-related mortality at $45 \%$ [13] for organ rupture and $41 \%$ for arterial complications.

\section{Secondary Complications of GI Surgery}

Postoperative complications were reported in the vascular subtype and rarely in other EDSs subtypes [24]. This is consistent with the predominant vessel- and GI-friability in the vascular subtype. Complications were most often recurrent arterial perforation or tears, recurrent bowel perforation or tears in $17 \%$, and recurrent hernia seen with a broad variance in frequency from $0 \%$ [27] to 20\% [23].

General surgical complications included excessive bleeding and poor wound healing. Generalized bleeding tendency due to fragility of capillaries and the perivascular connective tissue rather than clotting or platelet dysfunction, is a well-known feature of all subtypes of EDSs but with a wide range of severity within the different subtypes [32]. Studies reported excessive bleeding after surgery in $37 \%$ of patients with the vascular subtype while no data was available on other subtypes [27]. Neither was any data found on the mortality of surgery-associated bleeding.

In general, all patients with EDSs exhibit poor wound healing $[21,23]$, manifesting as tissue tears at minimal handling, suture dehiscence, fistula formation, fascial dehiscence $[13,23]$, and incisional herniation, occurring in up to $4.8 \%$ of the most exposed subgroup, the hypermobility type [24].

\section{Discussion}

This systematic review found that all EDSs subtypes were reported with a higher incidence of primary GI manifestations and complications in relation to surgical 
procedures, compared with the background population. The manifestations and complications are most predominant in the vascular subtype, which also holds the highest mortality of all subtypes and showed an approximately 3 times more frequent need for GI surgery. Of the acute GI complications, consisting of hollow and viscus organ rupture and GI hemorrhage, spontaneous perforation of the colon was most common, but tended to have a much lower mortality than vascular complications and solid organ rupture.

Currently, no causative treatment options exist for EDSs, but precautions are applicable to all subtypes of EDSs along with symptomatic treatment of complications. In general, patients with EDSs should be treated in specialized interdisciplinary centers with prior experience with EDSs, who can offer competent treatment. When examined, noninvasive imaging techniques are recommended, for example, CT, MRI, and ultrasonography. Specifically for vascular EDSs, avoidance of angiography is advised due to an associated complication rate of up to $67 \%$ and a mortality rate of up to $17 \%[23,33-35]$. Colonoscopies and gastroscopies are frequently performed in patients with EDSs [4] and reported with a 10\% risk of perforation in vascular EDSs, but likely safer in the remaining EDSs subtypes [36].

No official guidelines for the surgical management of patients with EDSs exist, but numerous recommendations in the published literature can be pooled to certain general instructions. Overall, a conservative approach and reservation of invasive treatment to vital indication is recommended [23]. Patients' previous surgical history, prior bleeding anamnesis, and subtype of EDSs should be taken into consideration when evaluating risks of surgical intervention in patients with EDSs [37]. This practice could possibly contribute to reduce the restraint on operating all patients with EDSs as one homogeneous group, as the surgical complications, as shown in this review, are primarily associated with the vascular subtype. Furthermore, and specifically for vascular EDSs, recommendations advocate to refrain from drugs that interfere with platelet function and coagulation [38, 39], and use of desmopressin as bleeding prophylaxis in patients with positive bleeding history. Regarding both general and regional anesthesia, patients with EDSs present a need for thorough preparation and pre-anesthetic considerations with particular attention to thoughtful peri-surgical patient positioning, previous intubation difficulties, and alertness on EDSs subtypes with increased vascular fragility. Local anesthesia possibly has a reduced or nil effect in patients with EDSs due to tissue scarring and reduced spread of local anesthetics, while peripheral nerve blockade is advised against in the vascular subtype due to the increased risk of bleeding. Likewise, refraining from neuraxial blockade in patients with vascular EDSs is recommended due to the increased vascular fragility, while the procedure is reported feasible and with preserved analgesic effect in other EDSs subtypes. However, neuraxial blockade should be performed with care to avoid a possibly increased risk of postdural puncture headache, considering possible meningeal cysts in the classic, hypermobility, and kyphoscoliotic type $[14,40]$.

The most frequently reported GI complication, the spontaneous colonic perforation, should be handled with a subtotal colectomy with closure of the rectal stump and permanent ileostomy as the safest approach. This reduces the possibility of recurrent perforation compared with the alternative primary end-to-end anastomosis $[13,23$, 41]. In younger patients, however, experience shows that restoration of GI continuity with a primary end-to-end ileorectal anastomosis is often preferred, in spite of the risk of re-perforation $[42,43]$. Lastly, it has been advised that prophylactic colectomy could be considered in patients with vascular EDSs with colonic ectasia or significant diverticulosis, to prevent spontaneous colonic rupture [23].

Currently, good clinical practice implies wound closing by suture with deep stitching with cutaneous stitches left in place twice as long as usual and preferably with additional fixation, preventing stretching of the scar $[1,38]$. It is also advised to apply sutures in 2 layers, cutaneous and subcutaneous, without extensive tension.

This review has several methodological strengths including a focused study question, adherence to the PRISMA-P and PRISMA guidelines, and publication of the protocol at PROSPERO. Additionally, it emphasizes the need for an official surgical guideline and how the overlapping clinical presentation of GI and vascular complications as acute abdominal pain, indicates how the surgical units must be capable of handling both acute vascular and GI insults. The review though has limitations as the literature search only identified retrospective observational studies with highly incomparable study designs and outcomes so that no meta-analysis was possible. Studies were all of a generally low methodological standard. Two of the studies [21, 22] were published before 1986, where the first official nosology for subgrouping, The Berlin Nosology [44], was determined. Consequently, these studies hold a great insecurity regarding their published subgrouping and related results, which are re- 
ferred to in this review. The studies only held a very limited number of patients, questioning the studies representation, and only one study presented a control group for comparison. Median NOS score was low and reflected several potential aspects of bias. Thus, some patients were identified through national foundations or medical genetic centers where patients must be considered significantly more prone to have developed complications compared to the background EDSs population, and consequently represent a risk of selection bias and an overestimation of the predefined outcomes in the true EDSs population. The predefined primary and secondary outcomes were predominantly reported in the included studies concerning vascular EDSs, suggesting a possible detection bias. The vascular subtype comprises only $5 \%$ of the gathered EDSs patient group [1,8], and is thus heavily overrepresented in research of complications regarding GI surgery. Lastly, the majority of the studies consisted of questionnaires and personal observational case series, presenting a notable risk of self-report bias. Thus, the included studies reflect how published literature within GI surgery in patients with EDSs almost exclusively consists of publications of low level of evidence. The abovementioned limitations can be considered as a natural consequence of EDSs being a rare disease. The limited number of diagnosed patients means that even orchestration of future RCT's will be difficult to actualize, and implies how current literature, mainly case reports and small-scale studies, still serves as a significant source of knowledge regarding EDSs and gastro-intestinal surgery.

In conclusion, patients with EDSs represent a surgical challenge with increased mortality and morbidity. Patients with the vascular subtype frequently demand acute surgery with a high risk of postoperative complications, while the remaining EDSs subtypes are affected to a lesser degree. However, no final conclusion regarding mortality and morbidity stratified by the different subtypes can be made due to the limited number and quality of the eligible studies. There are challenges in the surgical care of these patients, and intraoperative strategy may differ from normal routines in other patients. This could emphasize the need for the centralization of surgical treatment of patients with EDSs.

\section{Funding}

None.

\section{Disclosure Statement}

No conflicts of interest.

\section{Acknowledgments}

None.

\section{References}

1 De Paepe A, Malfait F: Bleeding and bruising in patients with Ehlers-Danlos syndrome and other collagen vascular disorders. Br J Haematol 2004;127:491-500.

2 Burcharth J, Rosenberg J: Gastrointestinal surgery and related complications in patients with Ehlers-Danlos syndrome: a systematic review. Dig Surg 2012;29:349-357.

3 Callewaert B, Malfait F, Loeys B, De Paepe A: Ehlers-Danlos syndromes and Marfan syndrome. Best Pract Res Clin Rheumatol 2008; 22:165-189.

4 Nelson AD, Mouchli MA, Valentin N, Deyle D, Pichurin P, Acosta A, Camilleri M: Ehlers Danlos syndrome and gastrointestinal manifestations: a 20-year experience at mayo clinic. Neurogastroenterol Motil 2015;27:16571666.

5 Solomon JA, Abrams L, Lichtenstein GR: GI manifestations of Ehlers-Danlos syndrome. Am J Gastroenterol 1996;91:2282-2288.

6 Reinstein E, Pimentel M, Pariani M, Nemec S, Sokol T, Rimoin DL: Visceroptosis of the bowel in the hypermobility type of EhlersDanlos syndrome: presentation of a rare manifestation and review of the literature. Eur J Med Genet 2012;55:548-551.

7 Beighton P, De Paepe A, Steinmann B, Tsipouras P, Wenstrup RJ: Ehlers-Danlos syndromes: revised nosology, Villefranche, 1997. Ehlers-Danlos National Foundation (USA) and Ehlers-Danlos Support Group (UK). Am J Med Genet 1998;77:31-37.

8 Allaparthi S, Verma H, Burns DL, Joyce AM: Conservative management of small bowel perforation in Ehlers-Danlos syndrome type IV. World J Gastrointest Endosc 2013;5:398401.

9 Sobey G: Ehlers-Danlos syndrome: how to diagnose and when to perform genetic tests. Arch Dis Child 2015;100:57-61.

10 De Paepe A, Malfait F: The Ehlers-Danlos syndrome, a disorder with many faces. Clin Genet 2012;82:1-11.

11 Bergqvist D, Björck M, Wanhainen A: Treatment of vascular Ehlers-Danlos syndrome: a systematic review. Ann Surg 2013;258:257261

12 Brooke BS, Arnaoutakis G, McDonnell NB, Black JH 3rd: Contemporary management of vascular complications associated with Ehlers-Danlos syndrome. J Vasc Surg 2010 51:131-138; discussion 138-139.

13 Pepin M, Schwarze U, Superti-Furga A, Byers PH: Clinical and genetic features of EhlersDanlos syndrome type IV, the vascular type. N Engl J Med 2000;342:673-680.

14 Wiesmann T, Castori M, Malfait F, Wulf $\mathrm{H}$ : Recommendations for anesthesia and perioperative management in patients with EhlersDanlos syndrome(s). Orphanet J Rare Dis 2014;9:109.

15 Liberati A, Altman DG, Tetzlaff J, Mulrow C, Gøtzsche PC, Ioannidis JP, Clarke M, Devereaux PJ, Kleijnen J, Moher D: The PRISMA statement for reporting systematic reviews and meta-analyses of studies that evaluate health care interventions: explanation and elaboration. J Clin Epidemiol 2009;62:e1-e34. 
16 Shamseer L, Moher D, Clarke M, Ghersi D, Liberati A, Petticrew M, Shekelle P, Stewart LA; PRISMA-P Group: Preferred reporting items for systematic review and meta-analysis protocols (PRISMA-P) 2015: elaboration and explanation. BMJ 2015;349:g7647.

17 PROSPERO, International Prospective Register of Systematic Reviews. http://www.crd. york.ac.uk/PROSPERO (accessed September 9, 2015).

18 The Clinical Trials Search Portal, World Health Organization. http://apps.who.int/ trialsearch/ (accessed September 20, 2015).

19 Covidence. Melbourne, Alfred Health, 2013. http://www.Covidence.org (accessed October 10, 2015)

20 Higgins J, Green S: Tools for Assessing Methodological Quality or Risk of Bias in NonRandomized Studies: Cochrane Handbook for Systematic Reviews of Interventions, Version 5.1.0. Oxford, Cochrane Collaboration, 2011.

21 Beighton PH, Murdoch JL, Votteler T: Gastrointestinal complications of the EhlersDanlos syndrome. Gut 1969;10:1004-1008.

22 Beighton PH: The Ehlers-Danlos Syndrome. London, William Heinemann Medical Books Limited, 1970.

23 Fogel S: Surgical failures: is it the surgeon or the patient? The all too often missed diagnosis of Ehlers-Danlos syndrome. Am Surg 2013; 79:608-613.

24 Castori M, Camerota F, Celletti C, Danese C, Santilli V, Saraceni VM, Grammatico P: Natural history and manifestations of the hypermobility type Ehlers-Danlos syndrome: a pilot study on 21 patients. Am J Med Genet A 2010;152A:556-564.

25 Liem MS, Van Der Graaf Y, Beemer FA, Van Vroonhoven TJ: Increased risk for inguinal hernia in patients with Ehlers-Danlos syndrome. Surgery 1997;122:114-115.

26 Rombaut L, Malfait F, De Wandele I, Cools A, Thijs Y, De Paepe A, Calders P: Medication, surgery, and physiotherapy among patients with the hypermobility type of Ehlers-Danlos syndrome. Arch Phys Med Rehab 2011;92: 1106-1112.

27 Oderich GS, Panneton JM, Bower TC, Lindor NM, Cherry KJ, Noel AA, Kalra M, Sullivan T, Gloviczki P: The spectrum, management and clinical outcome of Ehlers-Danlos syndrome type IV: a 30-year experience. J Vasc Surg 2005;42:98-106.

28 Ritelli M, Dordoni C, Venturini M, Chiarelli N, Quinzani S, Traversa M, Zoppi N, Vascellaro A, Wischmeijer A, Manfredini E, Garavelli L, Calzavara-Pinton P, Colombi M: Clinical and molecular characterization of 40 patients with classic Ehlers-Danlos syndrome: identification of 18 COL5A1 and 2 COL5A2 novel mutations. Orphanet J Rare Dis 2013;8:58

29 Shimaoka Y, Kosho T, Wataya-Kaneda M, Funakoshi M, Suzuki T, Hayashi S, Mitsuhashi Y, Isei T, Aoki Y, Yamazaki K, Ono M, Makino K, Tanaka T, Kunii E, Hatamochi A: Clinical and genetic features of 20 Japanese patients with vascular-type Ehlers-Danlos syndrome. Br J Dermatol 2010;163:704-710.

30 Kakadia N, Kanaki NS: Ehler Danlos syndrome: an overview. J Chem Pharmaceut Res 2011;3:98-107.

31 Germain DP: Clinical and genetic features of vascular Ehlers-Danlos syndrome. Ann Vasc Surg 2002;16:391-397.

32 Malfait F, De Paepe A: Bleeding in the heritable connective tissue disorders: mechanisms, diagnosis and treatment. Blood Rev 2009;23:191-197.

33 De Paepe A: The Ehlers-Danlos syndrome: a heritable collagen disorder as cause of bleeding. Thromb Haemost 1996;75:379-386.

34 Freeman RK, Swegle J, Sise MJ: The surgical complications of Ehlers-Danlos syndrome. Am Surg 1996;62:869-873.

35 Maltz SB, Fantus RJ, Mellett MM, Kirby JP: Surgical complications of Ehlers-Danlos syndrome type IV: case report and review of the literature. J Trauma 2001;51:387-390.

36 Wolf JL, Oza SS, Gautam S, Kilaru SM: Colonoscopies are not safe in patients with type 4 Ehlers-Danlos syndrome but appear to be safe with minimally increased rate of perforation in patients with other types of Ehlers-Danlos or Marfan syndrome. Gastroenterology 2015; 148(suppl 1):S407.

37 Dwivedi AJ, Hamdallah O, Morris ME, Yancey AE, Ross CB: Varying presentations in patients with symptomatic type IV vascular Ehlers-Danlos syndrome. Vasc Endovascular Surg 2012;46:163-166.

38 Castori M: Surgical recommendations in Ehlers-Danlos syndrome(s) need patient classification: the example of Ehlers-Danlos syndrome hypermobility type (a.k.a. joint hypermobility syndrome). Dig Surg 2012;29:453455.

39 Steinman B, Royce P, Superti-Furga A: The Ehlers-Danlos Syndrome: Connective Tissue and Its Heritable Disorders, ed 2. Hoboken, John Wiley \& Sons Inc., 2002, pp 431-523.

40 OrphanAnesthesia, Online Guideline 'Anaesthesia Recommendations for Patients Suffering from Ehlers-Danlos Syndrome'. http:// www.orphananesthesia.eu/en/rare-diseases/ published-guidelines/cat_view/61-rarediseases/60-published-guidelines/89-ehlersdanlos-syndrome.html (accessed June 30, 2016).

41 Beighton P, Horan FT: Surgical aspects of the Ehlers-Danlos syndrome. A survey of 100 cases. Br J Surg 1969;56:255-259.

42 Demirogullari B, Karabulut R, Demirtola A, Karabulut B, Gol IH, Aybay C, Symoens S, Sonmez K, Basaklar AC, Kale N: A novel mutation in the vascular Ehlers-Danlos syndrome: a case presenting with colonic perforations. J Pediatr Surg 2006;41:e27-e30.

43 Duthie G, Singh M, Jester I: Laparoscopic management of colonic complications in Ehlers-Danlos syndrome type IV. J Pediatr Surg 2012;47:e1-e3.

44 Beighton P, De Paepe A, Danks D, Finidori G, Gedde-Dahl T, Goodman R, Hall JG, Hollister DW, Horton W, McKusick VA, et al: International nosology of heritable disorders of connective tissue, Berlin, 1986. Am J Med Genet 1988;29:581-594. 